NASA Technical Memorandum 86937

\title{
The B2 Aluminides as Alternative Materials
}

Joseph R. Stephens

Lewis Research Center

Cleveland, Ohio

Prepared for the

\section{LIBAREY ROBPY \\ JUL 1985 \\ LANGLE RESSTAKA CEATER

1984 Fall Meeting of the Materials Research Society

Boston, Massachusetts, November 26-30, 1984 
ERRATA

NASA Technical Memorandum 86937

THE B2 ALUMINIDES AS ALTERNATIVE MATERIALS

Joseph R. Stephens

November 1984

The attached page of references ( $p .10)$ should be inserted in the report. 
THE B2 ALUMINIDES AS ALTERNATIVE MATERIALS

\author{
Joseph R. Stephens \\ National Aeronautics and Space Administration \\ Lewis Research Center \\ Cleveland, Ohio 44135
}

\title{
SUMMARY
}

As part of NASA's Conservation of Strategic Aerospace Materials (COSAM) Program, a research effort is underway to explore the potential of the B2 aluminides as structural material alternatives for the strategic element containing superalloys currently used in gas turbine engines. Emphas is is being place on the equiatomic $\mathrm{Fe}$ and $\mathrm{Ni}$ aluminides. Although $\mathrm{Co}$ is a strategic material, the equiatomic co aluminide is also being studied to gain a more complete understanding of these fourth period intermetallics. The research effort is a cooperative program involving in-house research at NASA Lewis plus several university grant programs. Research focuses on initial processing techniques such as ingot melting, powder metallurgy, and rapid solidification with and without additional thermomechanical processing; high temperature deformation primarily compressive creep; compositional effects within the binary B2 aluminides; third-element alloying addition effects on high temperature strength and oxidation resistance; and near room temperature ductility as influenced by processing, alloying, and grain size. This paper will review the various programs now underway and present some of the highlights of research results.

\section{INTRODUCTION}

NASA Lewis Research Center has a research program underway to identify alternate materials to the commonly used nickel-base superalloys utilized in gas turbine engines. This research effort was initially prompted by the cobalt shortage in the 1978 to 1980 time frame along with inflated prices of tantalum and niobium and the near 100 percent import dependence of each of these key elements as well as chromium. These four metals are used as alloying elements in nickel-base superalloys to improve strength ( $\mathrm{Ta}$ and $\mathrm{Nb}$ ), corrosion and oxidation resistance ( $\mathrm{Cr}$ and $\mathrm{Ta}$ ) and fabricability $(\mathrm{Co})$. In order to minimize the United States aerospace industry's dependence on these four metals, a program was initiated by NASA called Conservation of Strategic Aerospace Materials - COSAM (ref. 1). Two major thrusts of the program involve: (1) strategic element substitution and (2) alternate materials. Research in the first major thrust focused on understanding the role of the strategic elements in nickel-base superalloys and then identifiying nonstrategic substitutes (refs. 2 to 5 ). This phase of the program has been successful and is now nearing completion. The second major part of the COSAM Program - alternative materials, has focused on the B2 aluminides of $\mathrm{Fe}, \mathrm{Ni}$, and Co. Although cobalt was considered a strategic material, it is included in this research in order to gain a better understanding of the properties of this class of materials since the creep strength of COAl has been reported to be much greater than that of NiAl (ref. 6). The research program has been conducted by in-house investigations at NASA Lewis Research Center in conjunction with several university research programs. This paper will present an overview of the research now underway on the aluminide materials. 


\section{RESEARCH ON THE B2 ALUMINIDES}

Interest in the B2 aluminides stems from a number of reasons. As indicated by the phase diagrams for the three systems (figs. 1 (a) to (c)), equiatomic FeAl melts at $\sim 1600 \mathrm{~K}$ which makes it a candidate for intermediate temperature applications in gas turbine engines while stoichiometric CoAl and NiAl melt congruently at $\sim 1920 \mathrm{~K}$ which makes them candidates for higher temperature applications. The binary aluminides exist over a wide range of composition and have large solubilities for substitutional third element additions. Furthermore, the aluminides possess the potential for self-protection in oxidizing and/or corrosive environments, are relatively light-weight, and contain inexpensive readily available elements ( $\mathrm{Fe}, \mathrm{Ni}$, and $\mathrm{Al}$ ).

The equiatomic aluminides have the ordered $\mathrm{CsCl}$ cubic structure. This is important as it permits use of polycrystalline materials under cyclic temperature service whereas noncubic intermetallics, due to unequal thermal expansion along the principal axes, could be limited to single crystal forms for varying temperature exposures. The CsCl crystal structure is shown in figure 2 where possible slip vectors of $\langle 11\rangle\rangle,\langle 110\rangle$, and $\langle 100\rangle$ are indicated for slip or $\{110\}$ type planes. In general, slip is believed to occur only on the [110\} $<001>$ system in B2 intermetallics at low temperatures. If true, then extensive plasticity is not possible in polycrystalline materials because only three. independent slip systems exist. Limited room temperature ductility could be a major obstacle to the use of B2 aluminides. Fabricability can also be a problem with the $B 2$ aluminides.

In order to realize the potential of these materials, research efforts have focused on: high temperature deformation behavior of the binary aluminides; alloying to improve high temperature strength; oxidation resistance; near room temperature deformation behavior; and processing including powder metallurgy techniques, conventional casting, and rapid solidification. Current programs on the aluminides are summarized in figure 3 , along with the organizations involved. The bulk of the binary deformation studies are being conducted in-house at NASA Lewis Research Center where emphasis has been place on high temperature creep of powder metallurgy materials with variables such as composition, grain size, and test temperature being explored. In addition, thermal expansion behavior of the binary aluminides has been determined. To augment the in-house program, special emphasis was placed on understanding the mechanisms controlling deformation of the aluminides utilizing transmission electron microscopy techniques primarily through a grant at Stanford University (ref. 7). A second grant at Texas $A$ and $M$ University supports research utilizing the piezoelectric ultrasonic composite oscillator technique (PUCOT) to measure elastic modulii of the B2 intermetallics. There measurements are necessary to support modeling efforts. Detailed results of this study were presented earlier in this symposium by Harmouche and Wolfenden (ref. 8).

Alloying to improve high temperature strength is being conducted jointly by R.H. Titran of NASA Lewis and K. Vedula and co-workers from Case Western Reserve University. In a previous session of this symposium the effects of ternary additions to the FeAl intermetallic were described by Titran (ref. 9). Vedula, V. Pathare, and I. Aslanidis (ref. 10) of Case Western Reserve University have co-authored a paper to be presented later in this session on alloying of NiAl. The effects of alloying additions on high temperature oxidation resistance and on the ductile-brittle transition temperature are also under investigation. 
Studies of the effects of grain size, thermomechanical processing, and alloying on the near room temperature deformation behavior of NiAl were investigated by Schulson of Dartmouth College (ref. 11), and presented in an earlier session of this symposium. In the area of processing, both powder metallurgy techniques and arc melting followed by extrusion have been used to prepare samples of the intermetallics. In addition, rapid solidification processing (RSP) utilizing the melt spinning technique has been explored by $D$. Gaydosh of NASA Lewis and the microstructure of the melt-spun ribbon characterized by M. Crimp of Case Western Reserve University. A paper describing the results obtained on melt spun ribbons of FeAl and NiAl will be presented by these investigators (ref. 12) later in this session. Other processing techniques involving some of the newer melting and fabricating techniques are also being explored at NASA Lewis Research Center.

\section{HIGH TEMPERATURE PROPERTIES}

\section{Thermal Expansion}

Thermal expansion of the aluminides has been measured to provide basic information for (1) thermal stress and oxidation/corrosion modeling and (2) calculation of thermal vacancy concentration. This latter effort requires measurement of the overall thermal expansion $\left(\Delta 1 / 1_{0}\right)$ as well as the change in lattice parameter $\left(\Delta a / a_{0}\right)$ with temperature (ref. 13). The aluminides have complex point defect structures consisting of antistructure (substitutional) atoms and vacancies (refs. 14 to 16). In comparison to metals these aluminides can contain enormous numbers of vacant atom sites - approaching 10 percent for A1 rich alloys (refs. 16 to 18). Such large concentrations of vacancies could have a profound influence on mechanical properties.

Typical thermal expansion curves for the B2 aluminides from the work of clark and Whittenberger (ref. 19) are shown in figure 4 along with curves for several common classes of materials. The curves illustrate the significantly larger thermal expansion of FeAl in comparison to that of either COAl or NiAl. The data reveal that the expansion of $\mathrm{NiAl}$ is slightly greater than that of COAl between room temperature and $1273 \mathrm{~K}$. It was also shown that thermal expansion of all three intermetallics varies only slightly with composition. The large thermal expansion of $\mathrm{FeAl}$ compared with $\mathrm{Al}_{2} \mathrm{O}_{3}$ could pose problems from the standpoint of spalling of the oxide during cyclic heating and cooling. However, initial oxidation testing suggests that this is not the case.

Attempts to measure lattice parameters of the aluminides as a function of temperature and composition have been made. So far, experimental difficulties have resulted in inconsistent measurements. Steps are being taken to correct these problems.

\section{Binary Deformation Behavior}

During the course of a study on the slow plastic elevated temperature properties of powder metallurgy FeAl the rather unusual flow stress-composition dependence shown in figure 5 was observed by whittenberger (ref. 20). The only plausible explanation for the lower strength of $\mathrm{Fe}-39.8 \mathrm{All}$ and the higher

lunless noted otherwise, all compositions are in atomic percent. 
strengthsof $\mathrm{Fe}-43.2 \mathrm{Al}$ and $\mathrm{Fe}-45.7 \mathrm{Al}$ in comparison with other compositions seemed to be the grain size where small grain size resulted in stronger materials. The reason for this range of grain size is unclear since each alloy was extruded under nominally the same conditions. However, there could have been an inadvertent difference in time at temperature prior to extrusion or difference in cooling rates. To further explore this observation in more detail, a study was undertaken to examine the effects of thermomechanical processing on the elevated temperature strength of Fe-39.8 Al. Such treatments affected the grain sizes as summarized below:

\begin{tabular}{|c|c|c|}
\hline Extrusion parameters & $\begin{array}{l}\text { Heat } \\
\text { treatment }\end{array}$ & $\begin{array}{l}\text { Grain } \\
\text { size, } \\
\mu \mathrm{m} \\
\end{array}$ \\
\hline $\begin{array}{l}\text { Extruded at } 16: 1 \text { at } \\
1200 \mathrm{~K}\end{array}$ & None & 9 \\
\hline $\begin{array}{l}\text { Extruded at } 16: 1 \text { at } \\
1200 \mathrm{~K}\end{array}$ & $\begin{array}{r}16 \mathrm{hr} \text { at } \\
1300 \mathrm{~K}\end{array}$ & 11 \\
\hline $\begin{array}{l}\text { Compacted at } 1505 \mathrm{~K} \\
\text { and } 1420 \mathrm{MPa} ; \text { extruded } \\
\text { at } 16: 1 \text { at } 1505 \mathrm{~K}\end{array}$ & None & 55 \\
\hline $\begin{array}{l}\text { Compacted at } 1505 \mathrm{~K} \\
\text { and } 1420 \mathrm{MPa} ; \text { extruded } \\
\text { at } 16: 1 \text { at } 1505 \mathrm{~K}\end{array}$ & $\begin{array}{l}16 \mathrm{hr} \text { at } \\
1535 \mathrm{~K}\end{array}$ & 185 \\
\hline
\end{tabular}

Figure 6 presents typical transmission electron photomicrographs of the materials under investigation. Transmission microscopy and $x$-ray texture analysis confirmed that all the materials were polycrystalline recrystallized and contained few if any subgrains. The typical form of material resulting from the lower temperature extrusion (fig. 6(a)) possessed individual dislocations and necklace-like outlines of particles within and cutting across the grain boundaries. Such particles are probably due to prior oxides which resided on the original powder particle surfaces. Necklace-like structures were not observed in materials from the $1505 \mathrm{~K}$ extrusion; instead widely spaced particles and about $1 \mu \mathrm{m}$ diameter were found throughout the microstructure of the as-extruded material ( $\mathrm{fig} .6(\mathrm{~b})$ ), and somewhat larger particles (occasionally gathered in clumps) in the heat-treated material.

A11 materials were compression tested in air under constant velocity conditions at 1200,1300 , and $1400 \mathrm{~K}$ which are homologeous temperatures of about $0.75,0.81$, and 0.87 (based on the measured solidus temperature for $\mathrm{Fe}-39.8 \mathrm{Al}$. Typical $1300 \mathrm{~K}$ true stress-true strain diagrams are shown in figure 7 and are representative of the data for the other material conditions and temperature where the large grain size materials (55 and $185 \mu \mathrm{m}$ ) deformed at an approximately constant stress after $\sim 1$ percent strain while the smaller grain size (9 and $11 \mu \mathrm{m})$ aluminides exhibited continuous work hardening.

Flow stress-strain rate behaviors found for the $\mathrm{Fe}-39.8 \mathrm{Al}$ intermetallic are illustrated in figure 8 which shows that at $1200 \mathrm{~K}$ the small-grained intermetallics are stronger. However, this advantage is lost at a higher test temperature of $1300 \mathrm{~K}$ (fig. $8(\mathrm{~b})$ ).

For materials extruded at $1200 \mathrm{~K}$ strain rate-flow stress $(\varepsilon-\sigma)$ can be adequately described by a single stress exponent and activation energy. ( $k J$ ) where: 


$$
\dot{\varepsilon}=1.64 \times 10^{10} \sigma^{3.5} \exp -\left(\frac{449}{R T}\right)
$$

A similar analysis of the material extruded at $1505 \mathrm{~K}$ yields

$$
\dot{\varepsilon}=\mathrm{Co}^{5.4} \exp -\left(\frac{483}{\mathrm{RT}}\right)
$$

and $C$ is $9.7 \times 10^{9}$ for the extruded material and $1.8 \times 10^{11}$ for the extruded plus heat treated material.

These results suggest that the $10 \mu \mathrm{m}$ fine-grained (1200 $\mathrm{K}$ extruded materials) intermetaliics obey a deformation behavior proportional to a temperature independent stress exponent of 3.5 while larger grained-size material, 55 to $185 \mu \mathrm{m}$, obey a stress exponent term of $n=5.4$. The results further show that decreasing the grain size can effectively strengthen a $B 2$ aluminide to a homologeous temperature of at least 0.75 .

The results suggest that dislocation glide mechanism(s) are greatly influenced by grain size. The post test dislocation structure of the compression tested Fe-39.8 Al materials has been studied in detail by Krishnan (refs. 21 and 22) and typical transmission electron photomicrographs are shown in figures 9 and 10. These illustrate that: (1) no subboundaries are formed, (2) the dislocations are straight, and (3) the density, $\rho$, is low (fig. 10). Analys is of individual dislocations to determine character and Burger's vector ( $f i g .10$ ) indicates that all dislocations are of the edge nature with $\bar{b}=\langle 101\rangle$. This result was confirmed through use of a theoretical dislocation intensity computer program (ref. 23). Further examination of the structure revealed the existence of many dislocation pairs with $+b$ and $-b$ in the near vicinity of one another suggesting that dislocation recovery is governed by a simple annihilation process which produces the observed low dislocation density, $p \sim 10^{7} \mathrm{~cm}^{-2}$.

The stress-strain rate data for $\mathrm{Fe}-39.8 \mathrm{Al}$ have been further analyzed in terms of the Bailey Orowan creep model which envisages high temperature deformation as a competition between recovery and hardening processes. A typical result of this work is shown in figure 11 where the slope of the curve is the work hardening coefficient for creep and the intercept is the recovery rate.

Since $\dot{\sigma}$ and $\dot{\varepsilon}$ exhibited linear behavior, recovery rates and work hardening coefficients for creep could be readily calculated as functions of strain rate, temperature, and heat-treatment condition. Results for the small grain size $\mathrm{Fe}-39.8 \mathrm{Al}$ show that recovery rates are dependent upon temperature (fig. 12), strain rate, and to some extent, upon heat treatment. In contrast, the work hardening coefficient for creep is apparently independent of strain rate at all temperatures and independent of heat treatment at 1300 and $1400 \mathrm{~K}$.

The most puzzling results of this study are the very low hardening coefficients for creep in the intermetallic, approximately 0.0015 of the modulus at $1200 \mathrm{~K}$ based on extrapolation of data by Koester and Goedeche (ref. 24). Most results in the literature are greater than or equal to about 0.05 of the modulus of a given material and a similar value was obtained in this study (ref. 21) on an eutectic alloy $\gamma / \gamma^{\prime}-\alpha$ thus showing the model is capable of yielding reasonable hardening coefficients. Therefore, deformation in FeAl seems to follow different laws than metals. Evans and Knowles (ref. 25) have proposed a model which can account for a low work hardening coefficient for creep in a material which undergoes recovery controlled deformation. Through dislocation 
glide and climb processes, a three-dimensional network is established, and the maintenance of this network is responsible for creep. In their development it is predicted that hardening coefficient, $h$, is dependent upon the slip

distance, $s$ :

$$
h=\alpha \mu / 2 s_{\rho}^{0.5}
$$

where $\alpha$ is a constant about equal to one and $\mu$ is the shear modulus. A large value of $s$ would predict a low work hardening coefficient for creep. This seems to be the case for $\mathrm{Fe}-39.8 \mathrm{Al}$, as very few barriers to dislocation motion are found even in specimens tested to large strains at relatively high velocities as seen in the transmission electron microscopy photomicrographs (refs. 9 and 10) of as-extruded specimens tested at 1200 and $1300 \mathrm{~K}$.

In addition to the mechanical property results obtained for $\mathrm{Fe}-39.8 \mathrm{Al}$, the effects of aluminium content on the elevated temperature slow plastic flow behavior of binary $\mathrm{Fe}, \mathrm{Co}$, and $\mathrm{Ni}$ aluminides are being investigated. To date only the study of COAl for aluminum contents ranging form 43.65 to 51.31 percent has been completed. The vast majority of the constant velocity compression tests produced flow curves in which the stress rapidly increased during the first $\sim 1$ percent of deformation and then remained constant as was observed for large grain sized FeAl. Typical flow stress-strain rate curves for two COAl intermetallics are shown in figure 13. In this intermetallic Al content is important and this can best be illustrated by figure 14 where the stresses required to produce certain rates of deformation are shown as a function of composition. Clearly at faster strain rates the strength peaks near stoichiometry; however this advantage seems to be lessened at lower strain rates and higher temperatures. The effect of grain size on properties of COAI is uncertain as all materials had a small grain size $(\sim 10 \mu \mathrm{m})$ which was little affected by testing.

In terms of the traditional temperature compensated power law behavior, the activation energy and pre-exponential factor for the cobalt aluminides are dependent upon composition with both having their greatest magnitudes at $A 1 / C_{0}$ $\sim 0.975$. The stress exponent, on the other hand, seems to be independent of composition for $A 1 / C O>0.85$ where $n \sim 4.7$ as shown in Fig. 15. The highly Al deficient COAl materials apparently deform by a different mechanism than the other compositions.

The dislocation structures found in both as extruded and as-deformed samples of COAl have been studied by Nix (ref. 7) of Stanford University using transmission electron microscopy. Extensive dislocation networks and very coarse subgrains were found in the as-extruded material plus some isolated dislocations in the deformed material. The Burger's vectors of some of the dislocations have been determined to be $\langle 100\rangle$ and $\langle 110\rangle$. These dislocations would provide sufficient slip systems for general deformation. The scale of the dislocation substructure is much coarser than one would expect for a metal deformed at the same stress.

\section{Ternary Alloy Strengthening}

Strengthening of the near equiatomic B2 aluminides of $\mathrm{Fe}$ and $\mathrm{Ni}$ was investigated by Vedula and Titran and co-workers (refs. 27 and 28), via elemental ternary additions to pre-alloyed intermetallic powders. Alloying at the 2 and 
5 at $\%$ levels were selected on the basis of past experience in superalloy development. Due to the strong effect of boron on low temperature ductility in $\mathrm{Ni}_{3} \mathrm{Al}$ (ref. 29), boron was added at the $0.1 \mathrm{wt} \%$ levels. Microstructural examination of as extruded and heat-treated materials indicated they could be grouped into three broad categories based on the extent to which the 5 at $\%$ of the element diffused into the matrix after long term high temperature annealing for up to $175 \mathrm{hr}$ at temperatures in excess of 0.8 the melting temperature.

Class I alloys are single phase after homogenization indicating complete solubility and included the elements $\mathrm{Ti}, \mathrm{Co}, \mathrm{Ni}, \mathrm{Fe}, \mathrm{Mn}, \mathrm{Si}$, and to a certain extent, $\mathrm{Cr}$ and Re. Class II alloying additions were characterized by significant interdiffusion with the matrix, but without resulting in a single phase microstructure. Elements which belong to this category are $\mathrm{V}, \mathrm{Nb}, \mathrm{Zr}$, $\mathrm{Hf}$, and Ta. Class III elements Mo and $W$ did not exhibit any interdiffusion with the aluminide matrix. Typical photomicrographs of the three classes of microstructure are shown in figure 16.

True compressive flow stress-true compressive plastic strain curves for the alloys with ternary additions at the 5 at \% level were similar to the binary intermetallics, in general, exhibiting initial work hardening and then leveling off at a constant flow stress for true strains greater than 0.02 to 0.05 . Results of creep testing at $1300 \mathrm{~K}$ are shown in figures 17 and 18 for FeAl and NiAl alloys, respectively. The lines through the data points are drawn with a slope of 5 which seems to be the general trend for these alloys and the lines allow better comparison of the alloys. Quite clearly, for the FeAl alloys shown in figure 17, $\mathrm{Nb}$ and $\mathrm{Zr}$ alloy additions produce greater strengthening than other alloying elements. Both $\mathrm{Nb}$ and $\mathrm{Zr}$ belong to Class II elements, but it is not clear as yet whether this strengthening is due to solid solution effects and/or the effects of second phases present in the microstructure.

Ternary alloys of $\mathrm{Ni}$ were tested under constant load conditions rather than constant velocity conditions used in most of the other programs. The data shown in figure 18 are primarily for extruded and heat treated alloys, along with some alloys prepared by the Hot Isostatic Pressing (HIP) process. In addition data for two conventional superalloys tested under similar conditions are shown in comparison. The $\mathrm{Ta}, \mathrm{Nb}$, and $\mathrm{Hf}$ containing alloys are clearly far superior to the other NiAl alloys. These alloys are, in fact, comparable to the conventional superalloys. Once again, as for FeAl alloys, the trend seems to be for Class II alloys to be stronger than the others.

The comparison of the HIPped and hot extruded alloys for Mo and Mn additions along with the binary NiAl shows that the hot extruded material is superior to the HIPped material. The reason for this could be the better bonding in extruded alloys, since the shearing action during extrusion can break up the oxide layers on the individual powder particles. It should further be noted that the second phase particles in Class II alloys were aligned parallel to the extrusion direction and compression axis which may account for some of the strengthening achieved in these alloys. However, the coarse scale of the second phase particles makes it doubtful that they are the sole factor responsible for the improved strength of these alloys. Further studies are underway to determine the mechanism(s) by which the ternary additions improve the properties of the $\mathrm{B} 2$ aluminides. 


\section{Grain Size Effects}

Schuison (ref. 11) described the effects of grain size on the tensile ductility of NiAl near room temperature in an earlier session of this symposium. I would like to call attention to some of his earlier work (ref. 30 ) to show the dramatic effect of grain size on ductility. His work is based on the models of Cottre11 (ref. 31) and Petch (ref. 32) which state that the stress required to nucleate microcracks in coarse-grained materials is more that enough to propagate them. In contrast, for fine-grained materials the stress required to nucleate cracks is less than that required to propagate them. In the first case, coarse-grained materials will fail in a brittle manner while fine-grained material must undergo permanent deformation and work hardening prior to failure. The conclusion is therefore, that a critical grain size should exist for plastic flow. This does indeed appear to be the case for $\mathrm{Ni}-49 \mathrm{Al}$ at $673 \mathrm{~K}$ as illustrated by the results shown in figure 19 where the critical grain size is $\sim 20 \mu \mathrm{m}$. At lower temperatures the critical grain size becomes even smaller.

\section{Processing Techniques}

Early work on the aluminides in the 1960 's indicated that while tensile ductility could be achieved in single crystals at room temperature, polycrystalline materials produced by arc-melting were brittle. Advanced processing techniques give hope that improved low temperature ductility can be achieved in the B2 aluminides. Several of these new techniques are capable of producing very fine grain size material which, as we have just seen, is advantageous for low temperature ductility. One of these techniques is Rapid Solidification Processing (RSP). Gaydosh et a1. (ref. 33) have investigated melt spinning to improve the ductility of NiAl. Melt spun Ni-50 Al ribbon exhibited a columnar grain structure with an average grain length of $15 \mu \mathrm{m}$ and an average width of $5 \mathrm{~mm}$. Room temperature bend testing on as me1t-spun ribbon indicated an average failure strain of 0.9 percent while ribbons annealed for $1 \mathrm{hr}$ at $1273 \mathrm{~K}$ in helium exhibited an average strain to failure of 2.3 percent. Scanning electron microscopy examination of fracture surfaces showed that the as meitspun ribbon failed by almost entirely intergranular fracture (fig. 20(a)) while the heat treated ribbon possessed significant amounts of transgranular cleavage as shown in figure $20(\mathrm{~b})$. Schulson (ref. 30) has noted a similar change in fracture mode as grain size was reduced below the critical grain size for increased ductility. The fine grain size produced by rapid solidification processing is thought to contribute to the plastic deformation achieved at room temperature, however, since annealing improved the ductility of the melt spun material other factors such as segregation of impurities at grain boundaries must also play a role in the change of fracture mode and increase in ductility.

\section{CONCLUDING REMARKS}

NASA Lewis Research Center through a combined program of in-house research and university grants is investigating the potential of the $B 2$ aluminides as structural materials for high temperature applications in advanced heat engines. The program is aimed at understanding the mechanisms controlling both elevated temperature deformation where the materials may find applications and the near room temperature deformation behavior where limited ductility is a serious deterrent to their eventual use. 


\section{REFERENCES}

1. J.R. Stephens, NASA's Activities in the Conservation of Strategic Aerospace Materials, NASA TM-81617 (1980).

2. F.E. Sczezenie, and G.E. Maurer, in "COSAM Program Overview," pp. 21-36, NASA TM-83006 (1982).

3. R.N. Jarret, and J.R. Tien, Metal1. Trans. A, 13, 1021 (1982).

4. M.V. Natha1, R.D. Maier, and L.J. Ebert, Meta11. Trans. A, 13, 1767 (1982).

5. H.C. Nguyen, B.J. Pletka, and R.W. Heckel in Proceedings of the Conference on High Temperature Alloys: Theory and Design," ed. by J. Stiegler, AIME, New York, (1985). In press

6. L.A. Hocking, P.R. Strutt, and R.A. Dodd J. Inst. Met. 99, 98-101.

7. W.D. Nix in "COSAM" Program Overview: pp. 183-190, NASA TM-83006 (1982).

8. M.R. Harmouche, and A. Wolfenden, in "Proceedings of Materials Research Society, 1984 Fall Meeting," Elsevier Science Publishing Co., New York, (1985). To be published.

9. R.H. Titran, K.M. Vedula, and G.G. Anderson, [Editing Note-Same Info as \#8.]

10. K. Vedula, V. Pathare, I. Aslanidis, [Editing Note-Same Info as \#8.]

11. E.M. Schulson, [Editing Note-Same Info as \#8.]

12. D. Gaydosh, and M. Crimp, [Editing Note-Same Info as \#8.]

13. R.0. Simmons, and R.W. Ballutti, Phys. Rev. 125, 862 (1962).

14. N. Ridley, J. Inst. Met. 94, 255 (1966).

15. A.J. Bradley, and A.H. Jay, Proc. Roy. Soc. A, 136210 (1932).

16. A.J. Bradley, and A Taylor, Proc. Roy. Soc. A, 15956 (1937).

17. R. Meyer, E. Waschte, and V. Gerold, Z. Metalkd. 67, 97 (1976).

18. D. Paris, P. Lesbats, J. Nuc1. Mater. 69-70, 628 (1978).

19. R.W. Clark, and 3.D. Whittenberger, in "Proceedings of the 8 th International Thermal Expansion Symposium," ed. by T.A. Hahan, Plenum Press, NY (1984), pp. 189-796.

20. J.D. Whittenberger, Mater. Sci. Eng. 57, 77 (1983).

21. J.D. Whittenberger, and R.V. Krishnan, J. Mater. Sci. 19, 509 (1984).

22. R.V. Krishnan, Private Communication. 
23. A.K. Head, P. Humble, L.M. Clarebrough, A.J. Morton, and C.T. Forewood, in "Defects in Crystalline Solids, vol. 7, "American Elsevier Publishing Company, Inc., (1973).

24. W. Koester, and T. Goedeche, 2. Metallkd 73, 111 (1982).

25. H.E. Evans, G. Knowles, in "Creep and Fracture of Engineering Materials and Structures," ed. by B. Wilshire and D.R.J. Owen, Pineridge Press, Swansea (1983), p. 169.

26. J.D. Whittenberger, Mater. Sci. Eng. (1985). To be published.

27. K. Vedula, G. Anderson, V. Pathare, and I. Aslanidis, in "Proceedings of the International Powder Metallurgy Conf.," Toronto. (1984).

28. V. Pathare, K. Vedula, and R.H. Titran, [Editing Note-Same Infor as \#27.]

29. C.T. Liu, C.L. White, C.C. Koch, and E.H. Lee, in "High Temperature Materials Chemistry II." ed. by Munir, Electrochemical Society. Proceedings Volume 83-7 (1983), pp. 32-41.

30. E.M. Schulson, and D.R. Barker, Scr. Meta11. 17, 519 (1983).

31. A.H. Cottre11, Trans. AIME 212192 (1958).

32. N.J. Petch, Phil. Mag. 3, 1089 (1958).

33. D.J. Gaydosh, R.W. Jech, and R.H. Titran, J. Mater. Sci. Lett. (1985). To be published. 


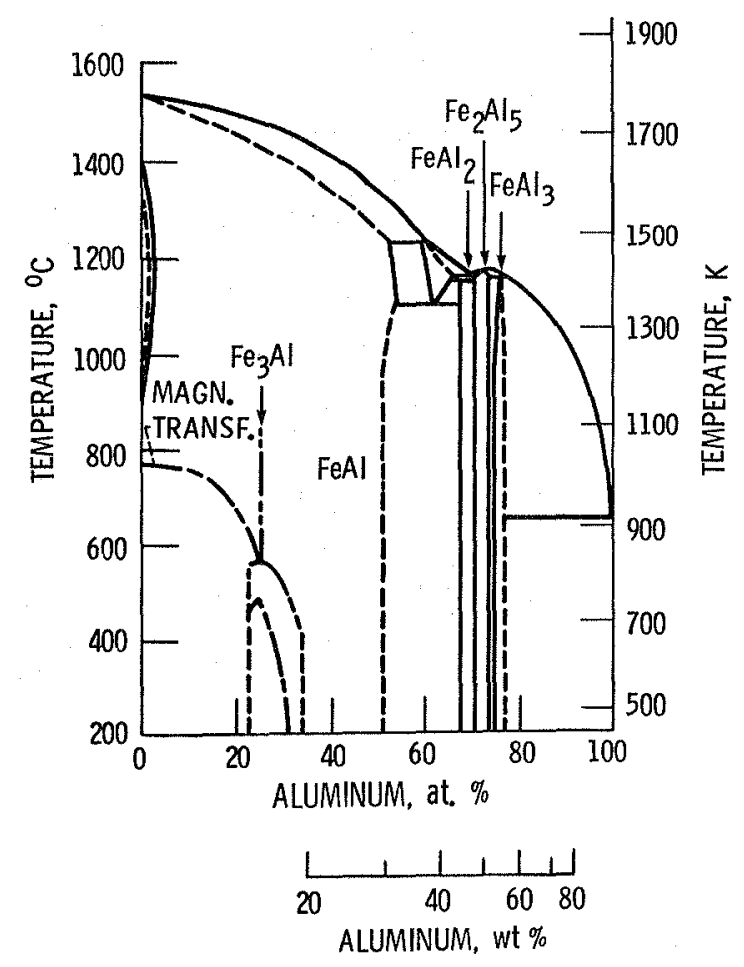

(a) Iron-aluminum.
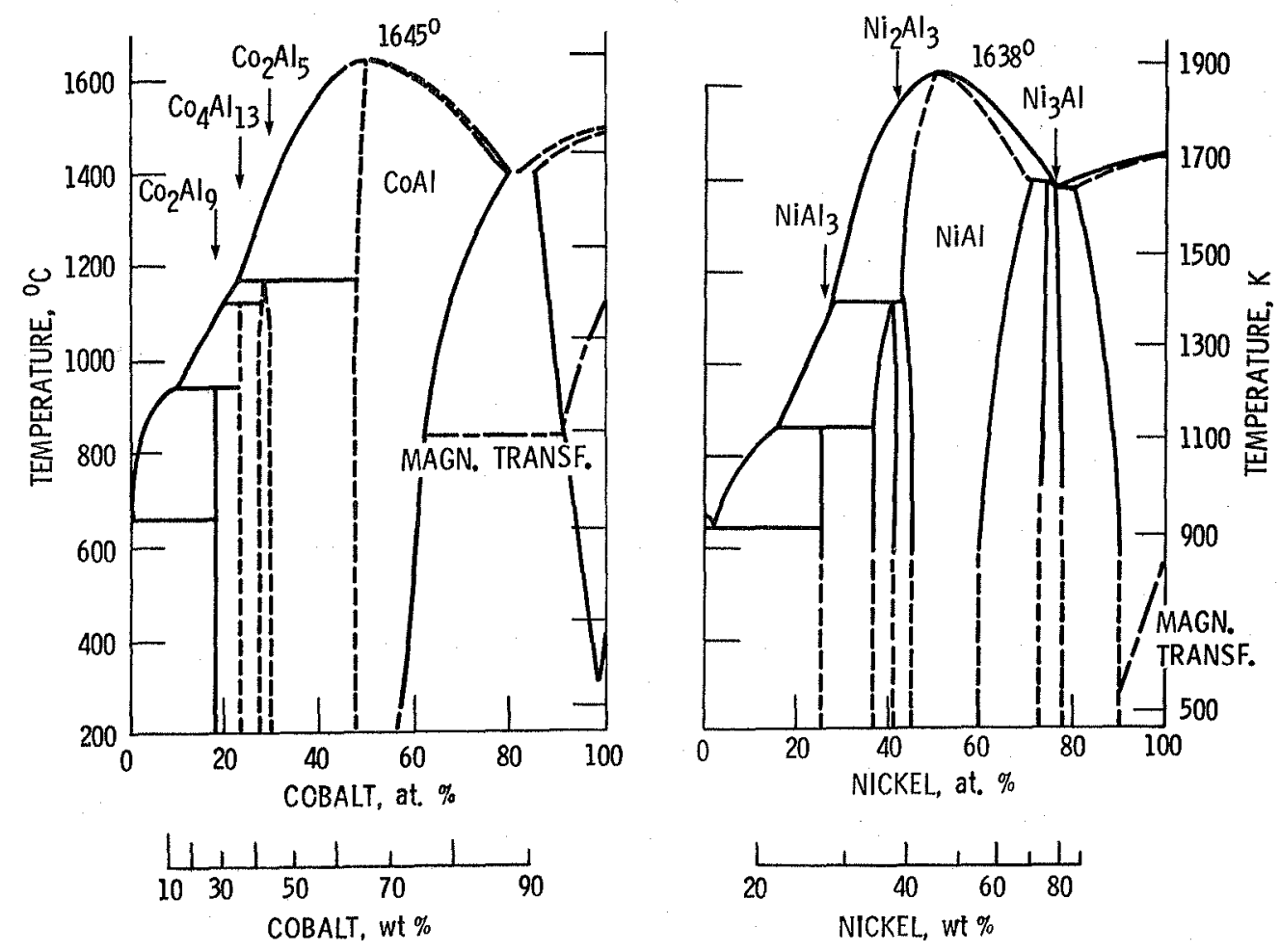

(b) Cobalt-aluminum.

(c) Nickel-aluminum.

Figure 1. - Phase diagrams of the Fe, Co, and Ni-Al systems. 


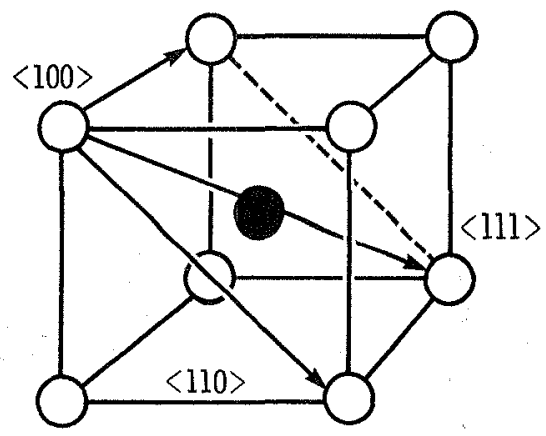

Figure 2. - $\mathrm{CsCl}(\mathrm{B} 2)$ crystal structure and possible $\langle 100\rangle$, $\langle 110\rangle$, and $\langle 111\rangle$ slip vectors on $\{110\}$ planes for the near equiatomic aluminides.

* THERMAL eXPANSION

* DEFORMATION BEHAVIOR

* DEFORMATION MECHANISMS

*** MODULUS DETERMINATION

$* *$ HIGH TEMPERATURE STRENGTHENINGALLOYING

OXIDATION RESISTANCE

* TMPIALLOYING TO IMPROVE LOW TEMPERATURE DUCTILITY

$* \%$ RAPID SOLIDIFICATION PROCESSING

ADVANCED PROCESSING TECHNIQUES PHASE DIAGRAMS
NASA LEWIS

NASA LEWIS

NASA LEWIS/STANFORD UNIVERSITY

TEXAS A AND M UNIVERSITY

NASA LEWIS / CASE WESTERN RESERVE UNIVERSITYITRW

NASA LEWIS

DARTMOUTH COLLEGE/CASE WESTERN RESERVE UNIVERSITY

NASA LEWIS/CASE WESTERN RESERVE UNIVERSITY

NASA LEWIS/GENERAL ELECTRIC CO.

ASM/IIT

* TO BE DISCUSSED IN THIS PAPER

$\because$ TO BE PRESENTED BY OTHER AUTHORS AT THIS SYMPOSIUM

Figure 3. - Summary of NASA Research Program on the B2 aluminides. 


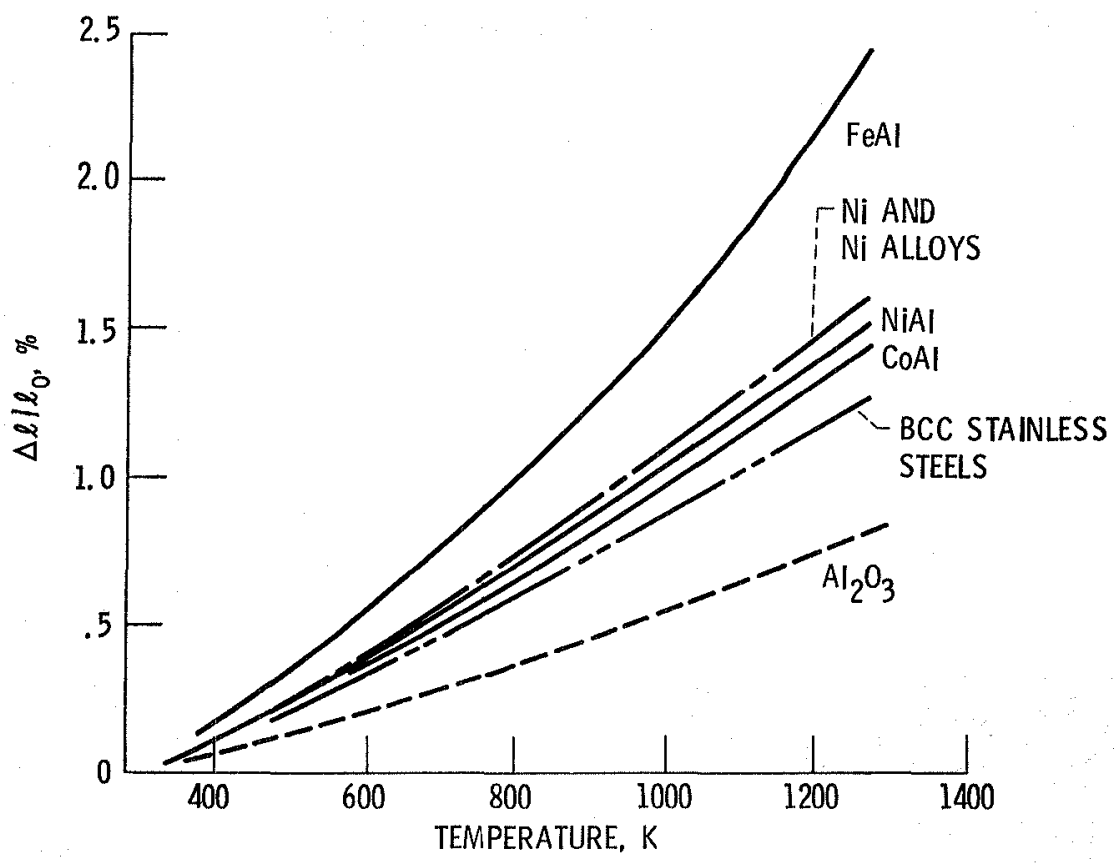

Figure 4. - Comparison of thermal expansion of the B2 aluminides, several common alloys, and alumina.

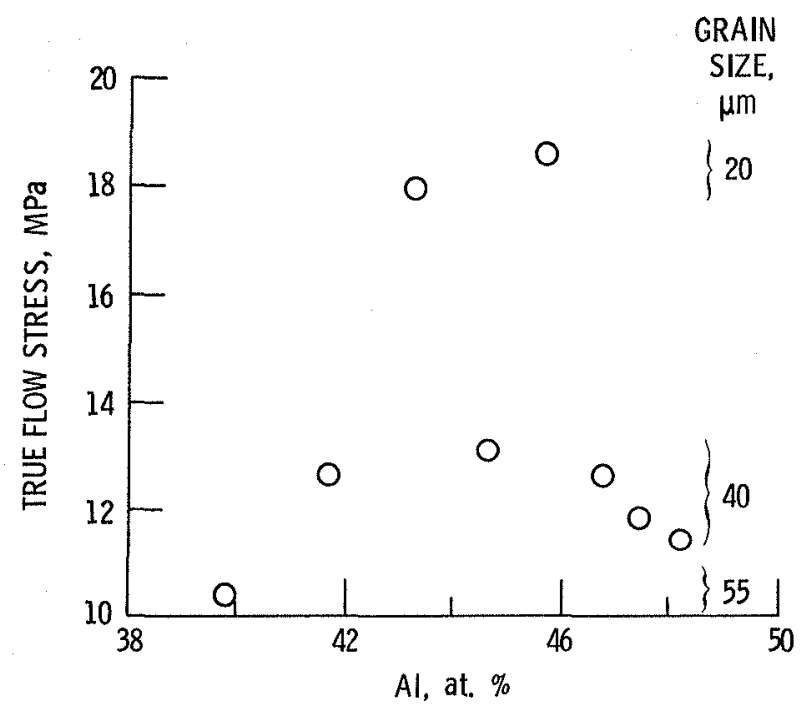

Figure 5. - Effect of aluminum content and grain size on flow stress to produce a strain rate of about $2 \times 10^{-4} \mathrm{~s}^{-1}$ at $1300 \mathrm{~K}$ in FeAl. 


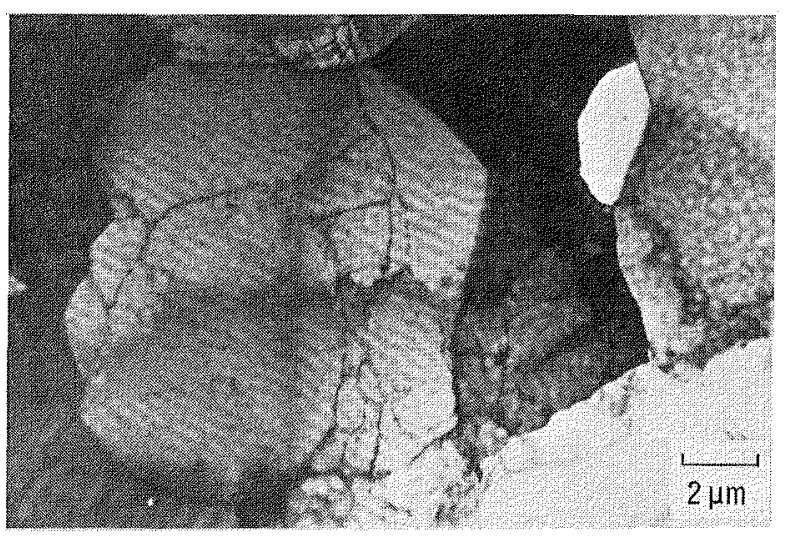

(a) Prepared by extruding at $1200 \mathrm{~K}$ plus $16 \mathrm{~h}$ at $1300 \mathrm{~K}$ (11 $\mu \mathrm{m}$ grain size).

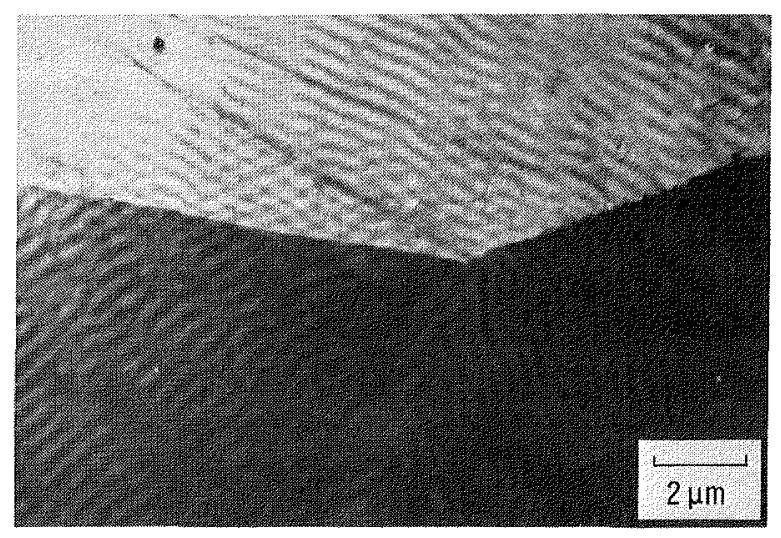

(b) Prepared by extruding at $1505 \mathrm{~K}$ (55 $\mu \mathrm{m}$ grain size).

Figure 6. - TEM photomicrographs of Fe $-39.8 \mathrm{Al}$ material. 


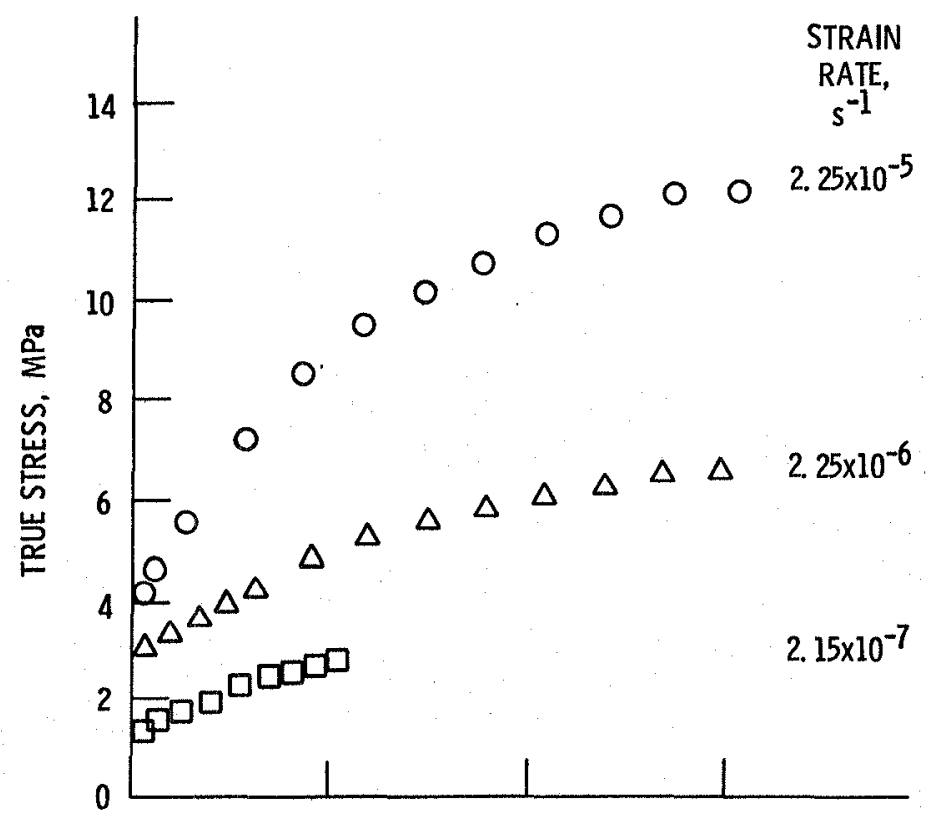

(a) Extruded at $1200 \mathrm{~K}$ plus $16 \mathrm{hr}$ at $1300 \mathrm{~K}$; grain size, $11 \mu \mathrm{m}$.

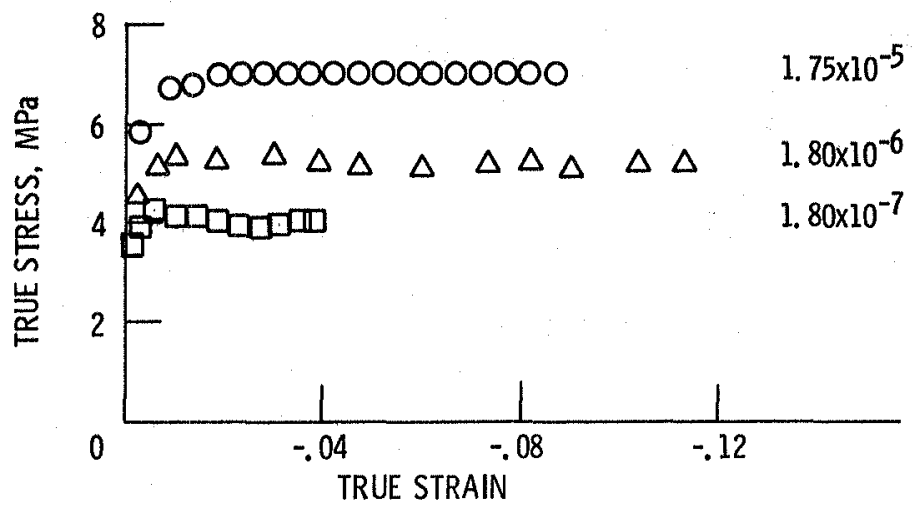

(b) Extruded at $1505 \mathrm{~K}$; grain size, $55 \mu \mathrm{m}$.

Figure 7. - True stress/true strain compression test curves at $1300 \mathrm{~K}$ for $\mathrm{Fe}-39.8 \mathrm{Al}$ materials prepared by extruding at $1200 \mathrm{~K}$ plus $16 \mathrm{hr}$ at $1300 \mathrm{~K}$ and extruding at $1505 \mathrm{~K}$. 


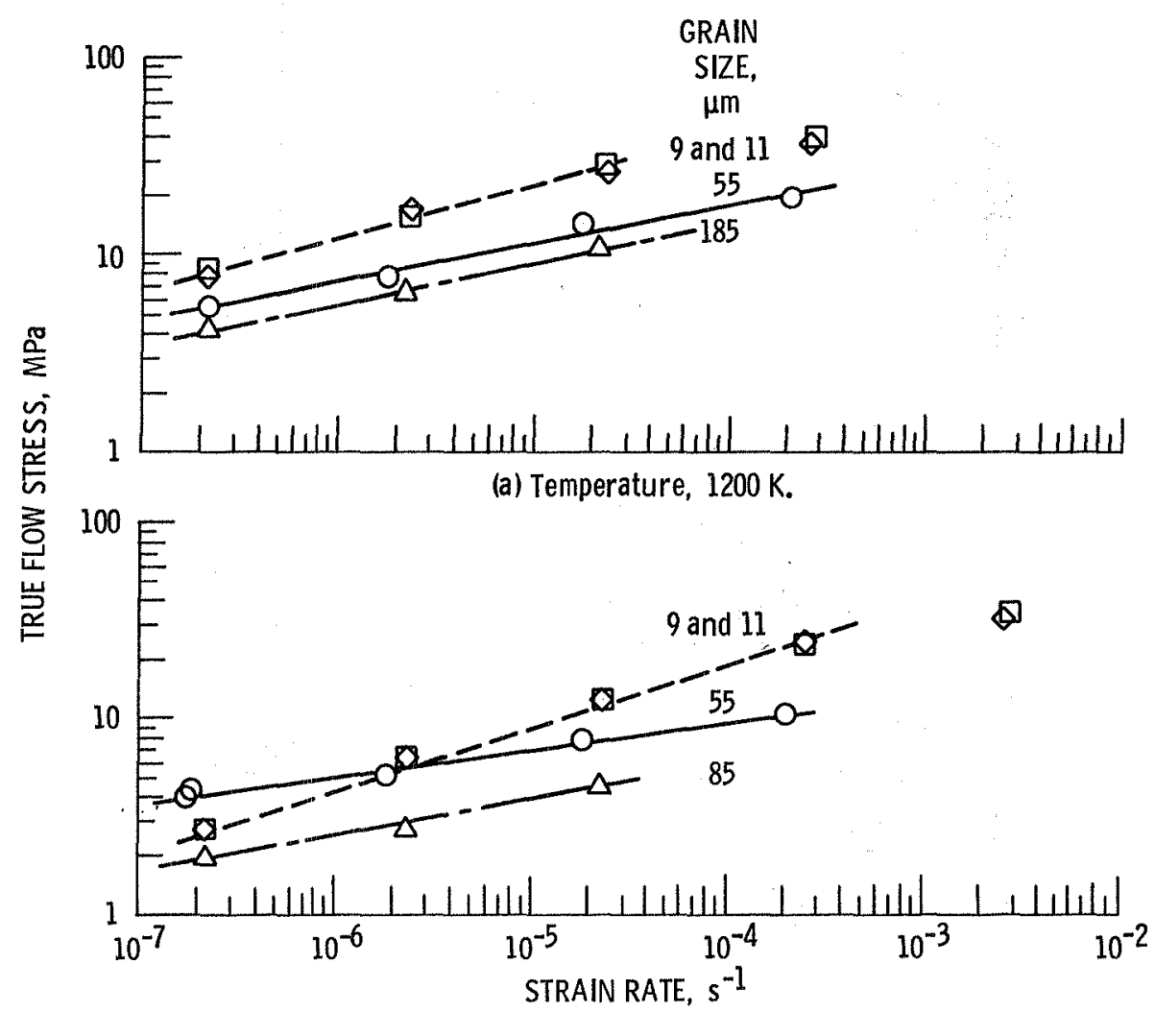

(b) Temperature, $1300 \mathrm{~K}$.

Figure 8. - True flow stress-strain rate curves for Fe-39. 8AI materials. 


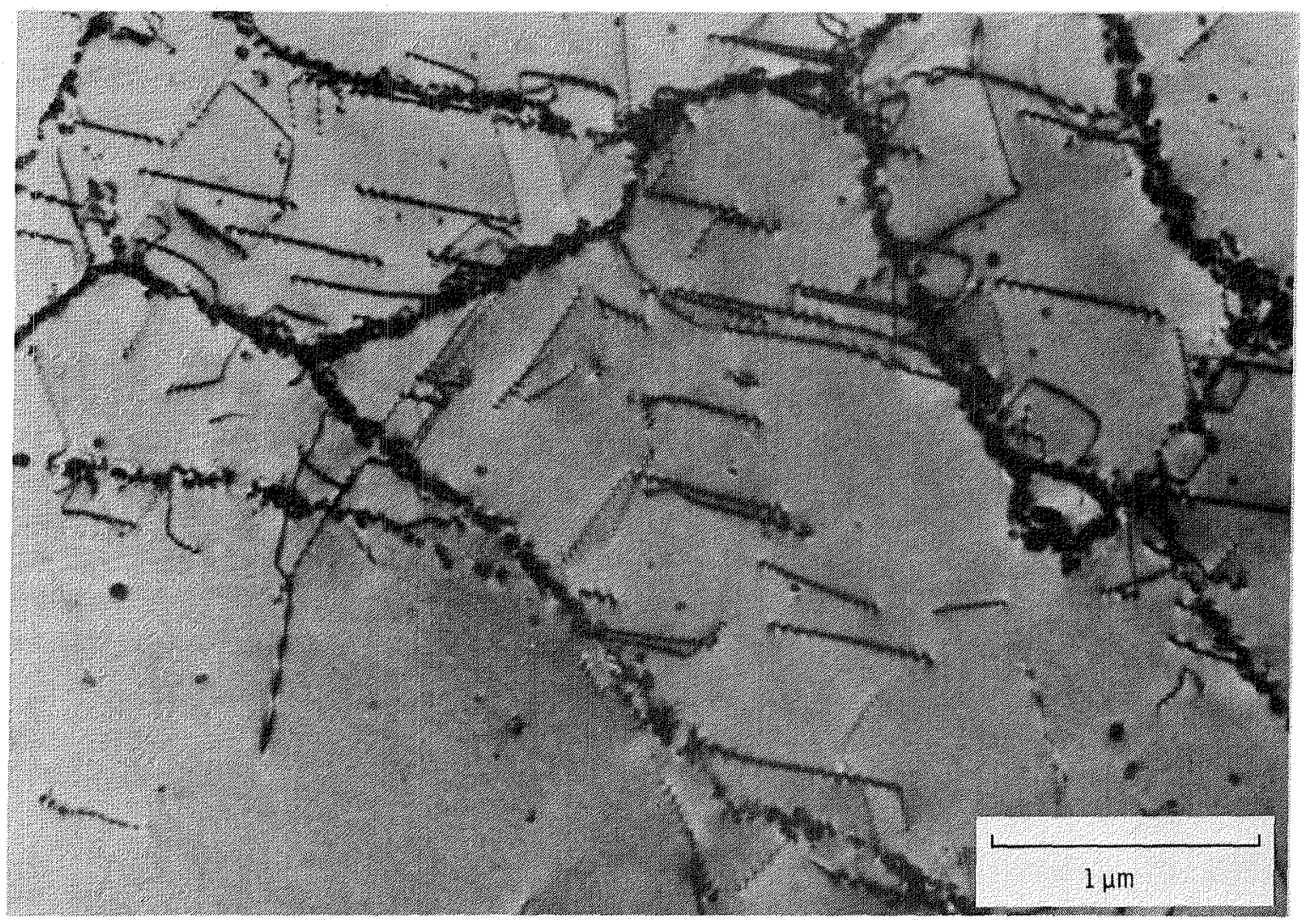

Figure 9. - Fe-39.8 Al tested at $1300 \mathrm{~K}$ and $\varepsilon \sim 2.1 \times 10^{-4} \mathrm{~s}^{-1}$ to $-28.4 \%$ strain. No sub boundaries formed even after $\sim 30 \%$ defor mation; low dislocation density; and straight dislocations. 


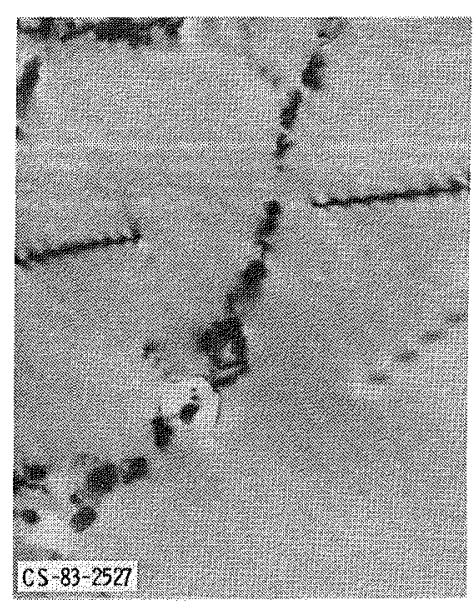

$\mathrm{g}=10 \overline{\mathrm{l}}$

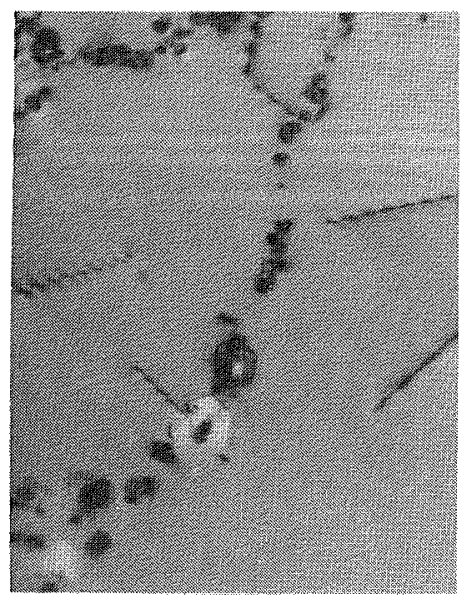

$\mathrm{g}=01 \overline{\mathrm{l}}$

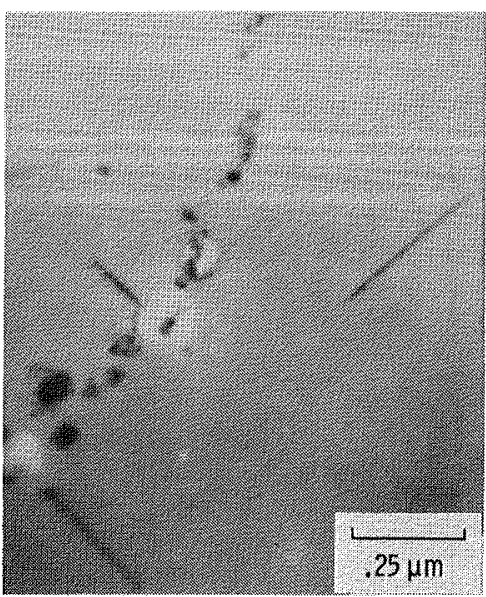

$g=\overline{1} \overline{1}$

Figure 10. $-\mathrm{Fe}-39.8 \mathrm{Al}$ tested at $1200 \mathrm{~K}$ and $\varepsilon \sim 2.1 \times 10^{-7} \mathrm{~s}^{-1}$ to $4.7 \%$ strain. Photomicrographs show loss of visibility for $b=10 \overline{1}$ then $g \cdot b$ yields 2,1 , and 0 , going from left to right for the noted dislocations.

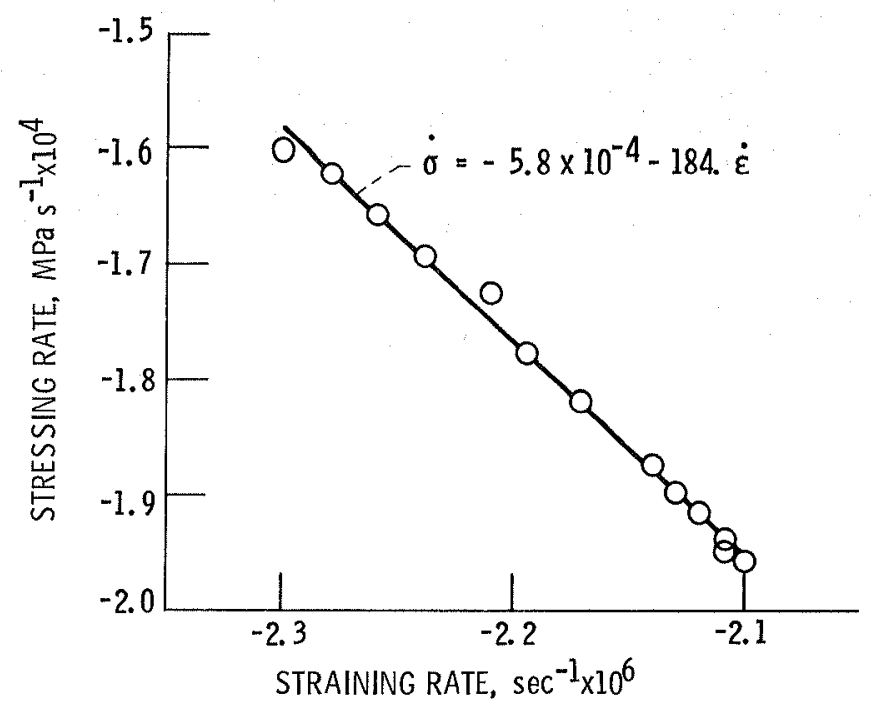

Figure 11. - Typical stressing rate/straining rate curves for as-extruded $\mathrm{Fe}-39.8 \mathrm{Al}$ tested at a constant velocity of $2.12 \times 10^{-5} \mathrm{~mm} \mathrm{~s}^{-1}$ at $1200 \mathrm{~K}$. 


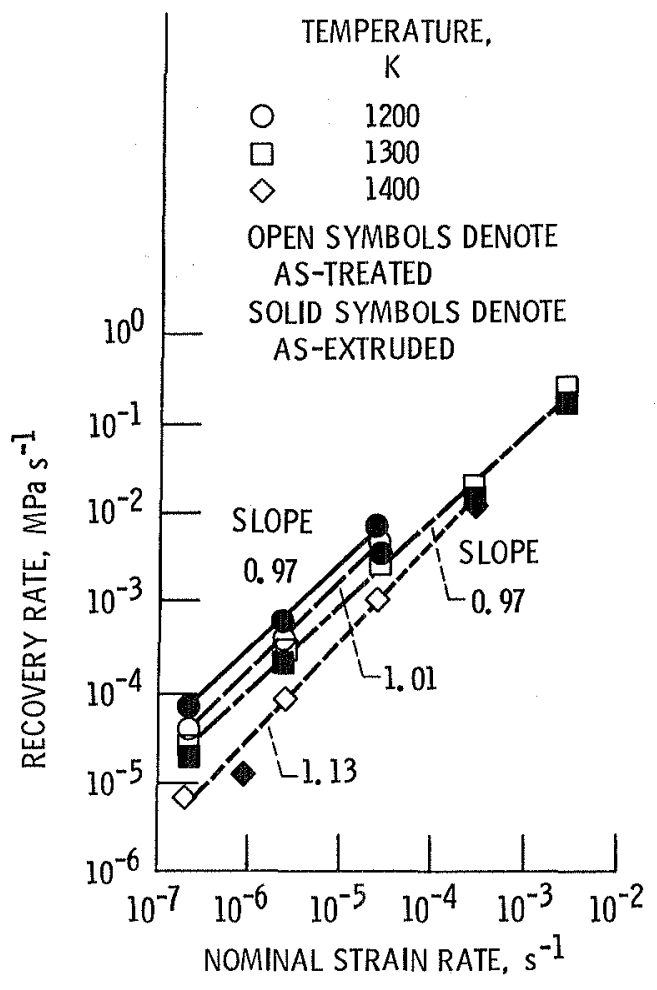

(a) Recovery rates.

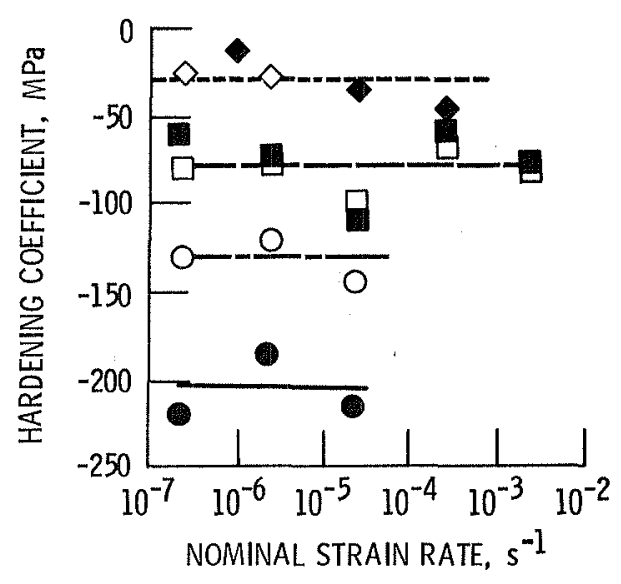

(b) Work hardening coefficients for creep.

Figure 12. - Recovery rates and work hardening coefficients for creep as functions of nominal strain rate and temperature for $\mathrm{Fe}-39.8 \mathrm{Al}$ materials. 


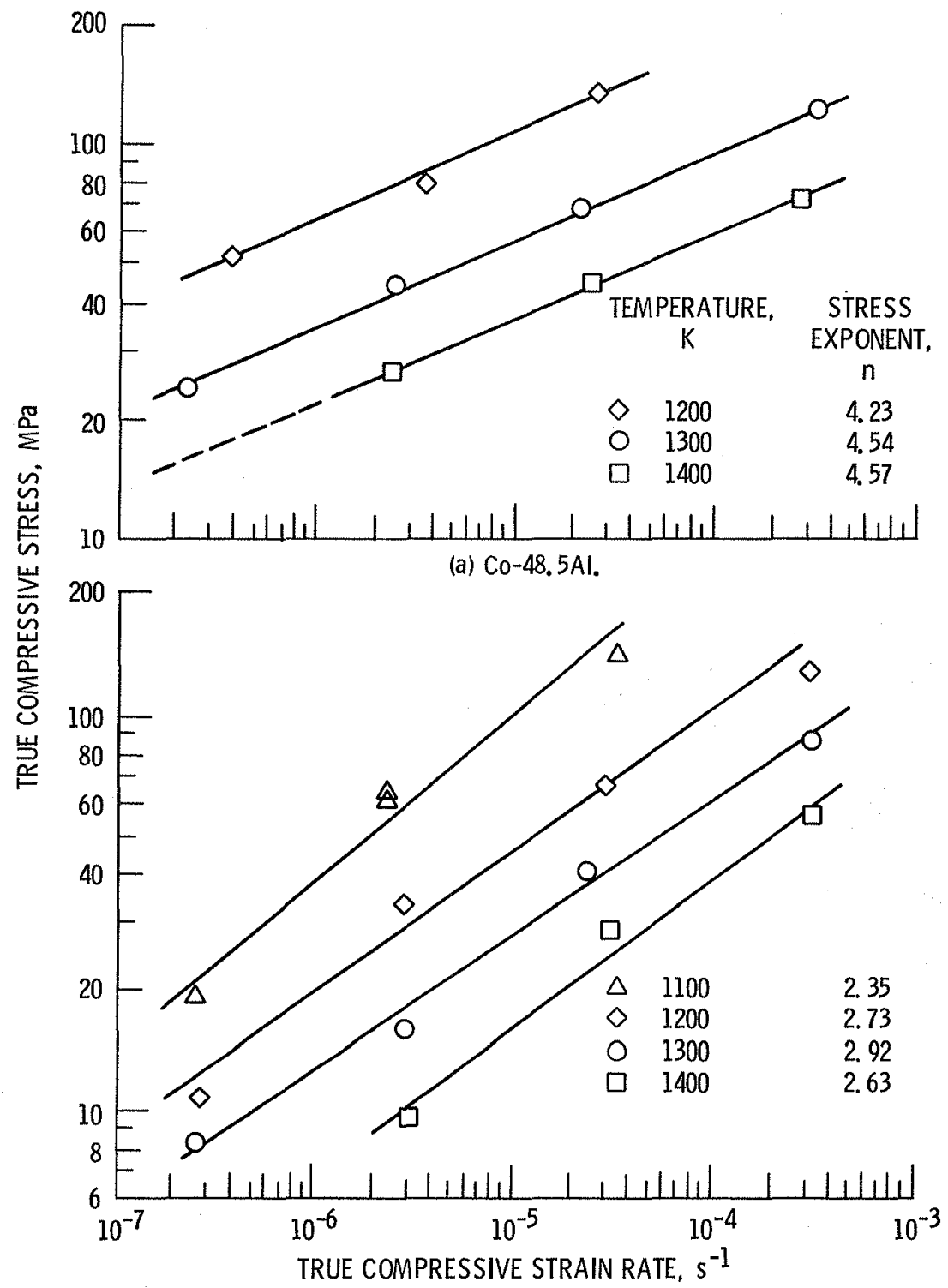

(b) $\mathrm{C} 0-43.7 \mathrm{Al}$.

Figure 13. - Compressive flow stress-strain rate behavior of $\mathrm{Co}-48.5 \mathrm{Al}$ and $\mathrm{C}_{0}-43.7 \mathrm{Al}$ as a function of temperature. 


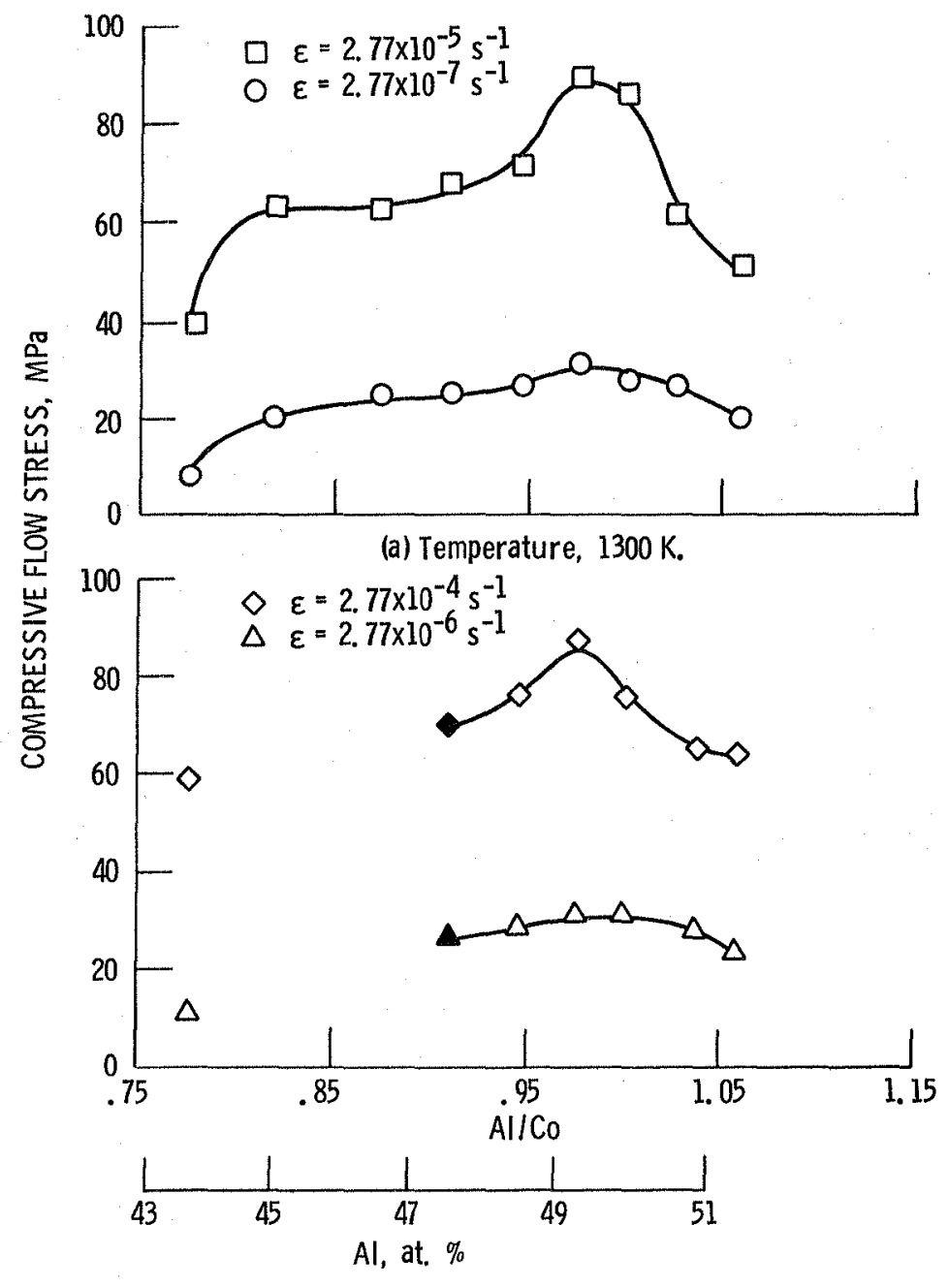

(b) Temperature, $1400 \mathrm{~K}$.

Figure 14. - Flow stresses necessary to produce several strain rates. 


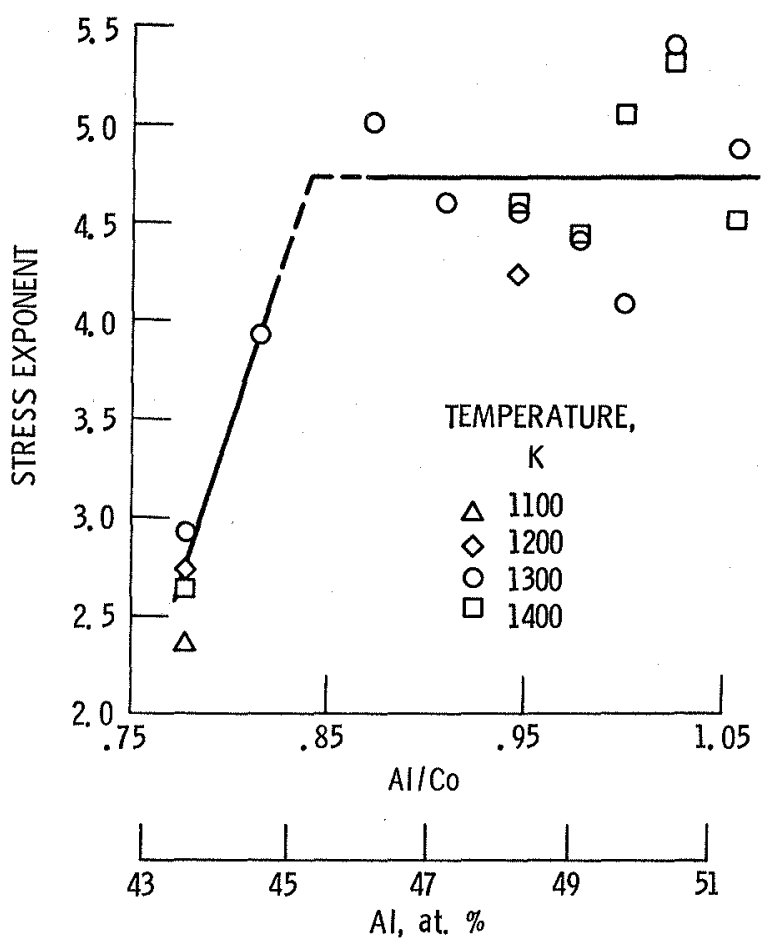

Figure 15. - Stress exponents as a function of composition in binary CoAl materials. 


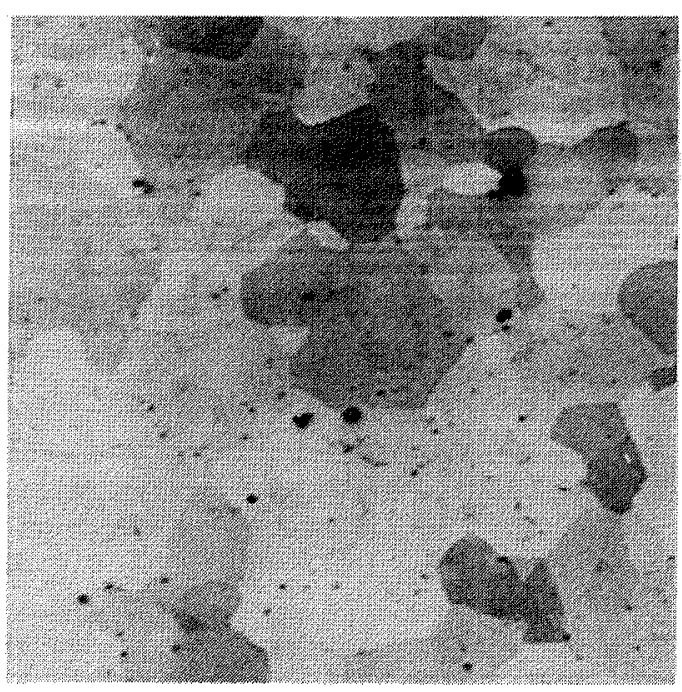

Class I Fe-Mn

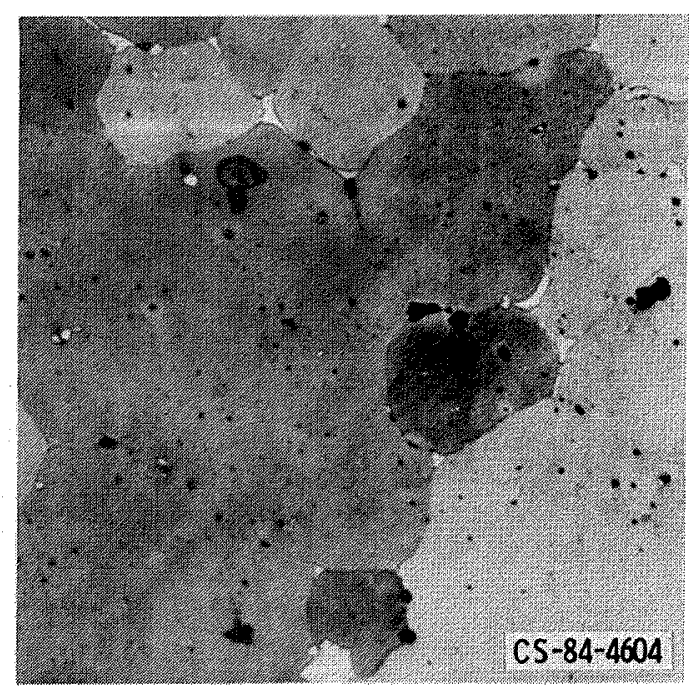

Class II Fe-5 Ta

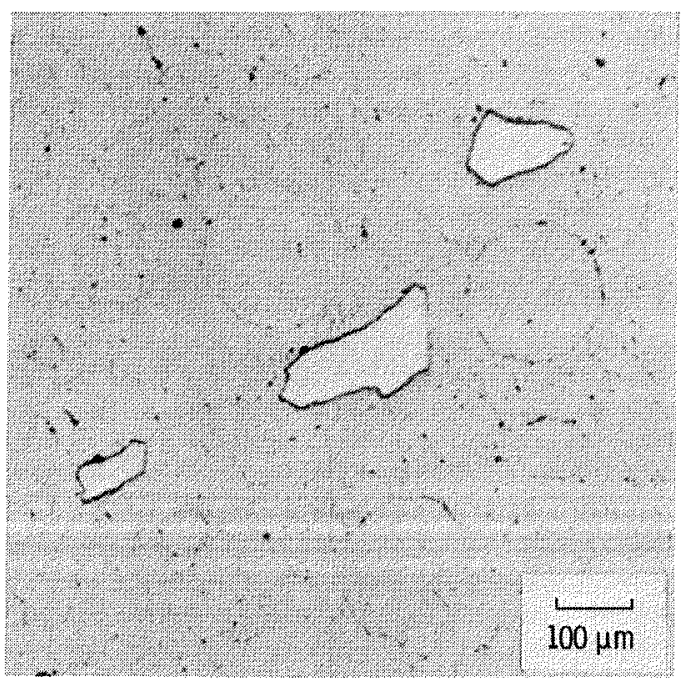

Class III Fe-5 Mo

Figure 16. - Microstructures of FeAl ternary alloys。 


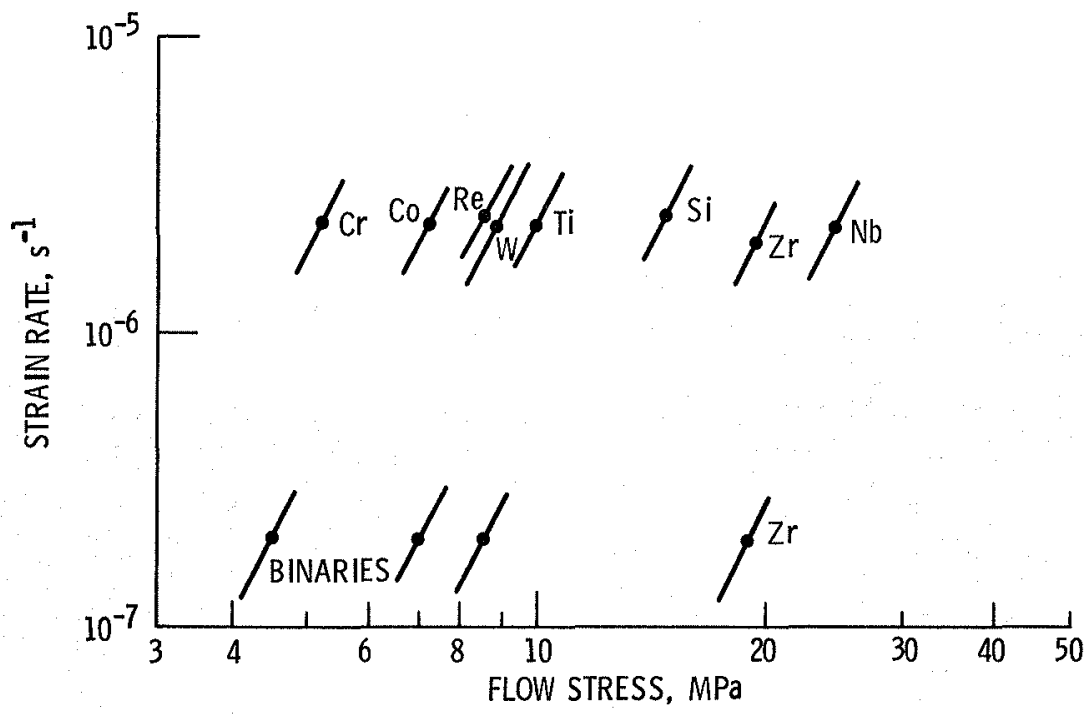

Figure 17. - Results of hot compression testing of several FeAl alloys at $1300 \mathrm{~K}$. Lines drawn through the data points are the approximate slopes expected.

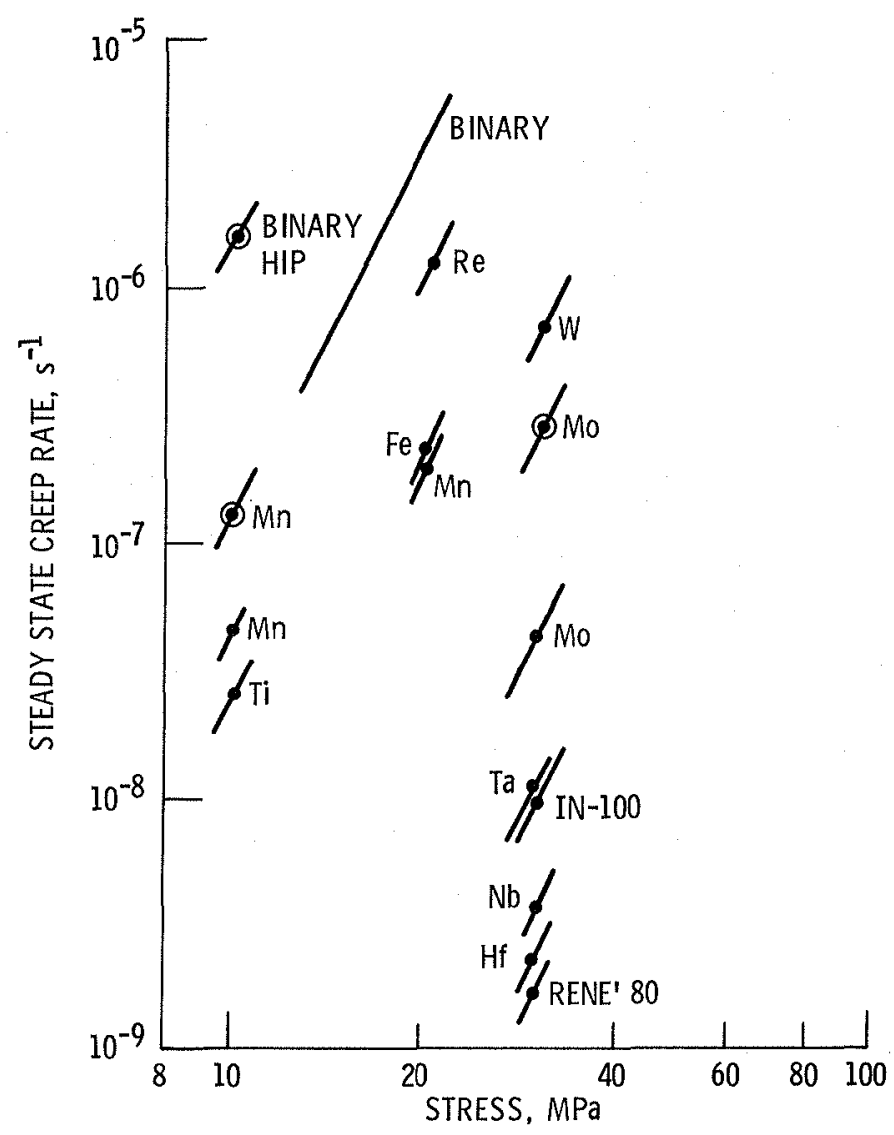

Figure 18. - Compressive creep data for several NiAl alloys tested at $1300 \mathrm{~K}$ compared with some conventional superalloys. Lines drawn through data points are expected slopes. 

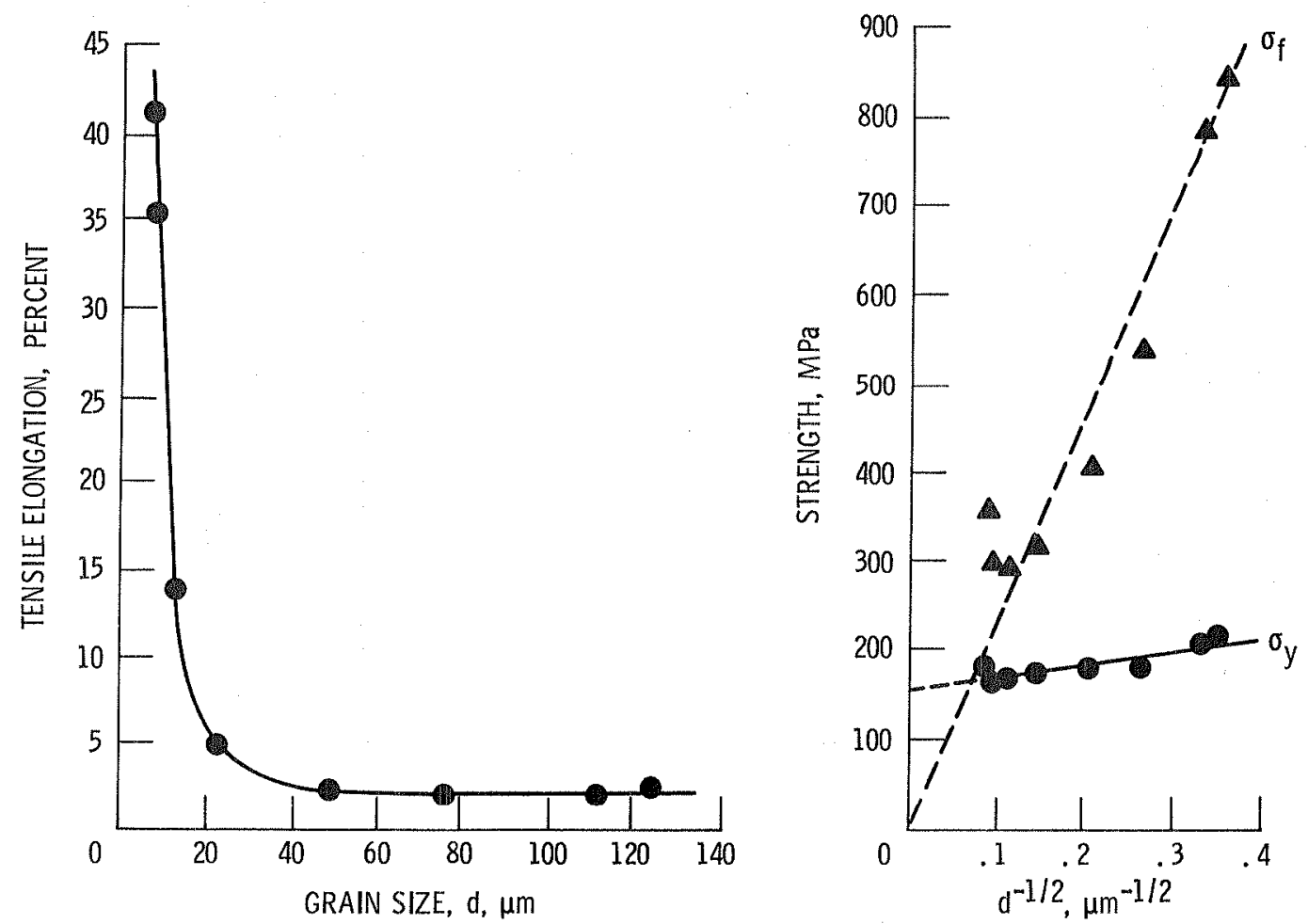

Figure 19. - Effect of grain size, $d$ on tensile elongation, yield strength, $\sigma_{y}$ and fracture strength, $\sigma_{f}$ of NiAl at $673 \mathrm{~K}$.

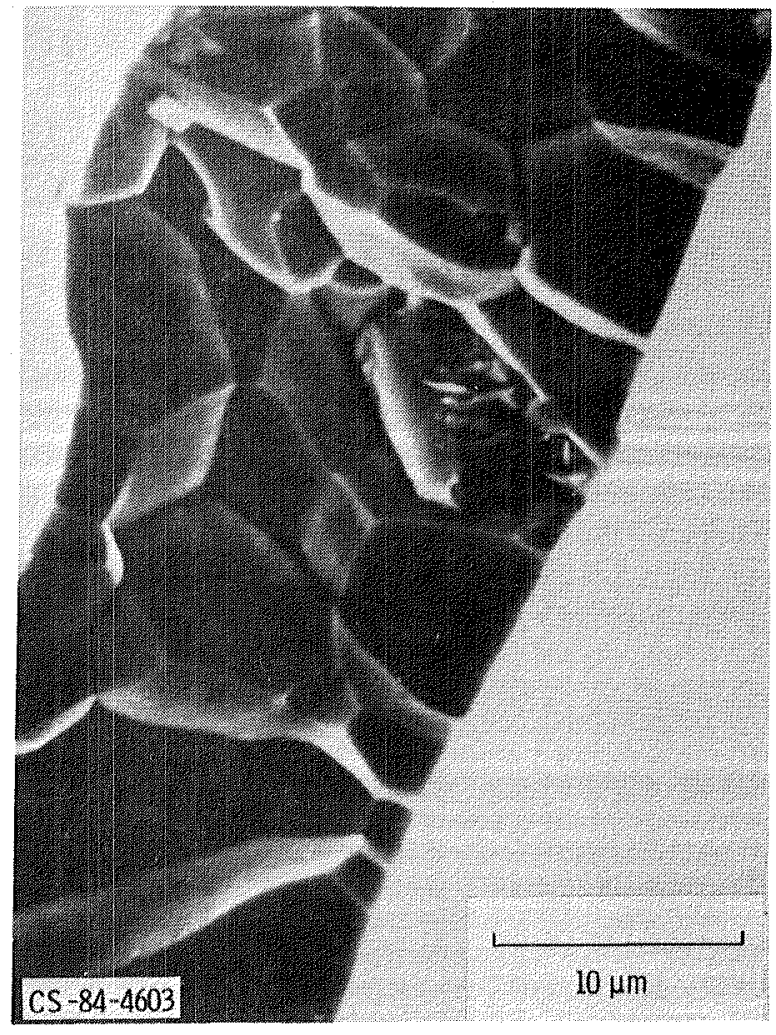

(a) As-spun ribbon.

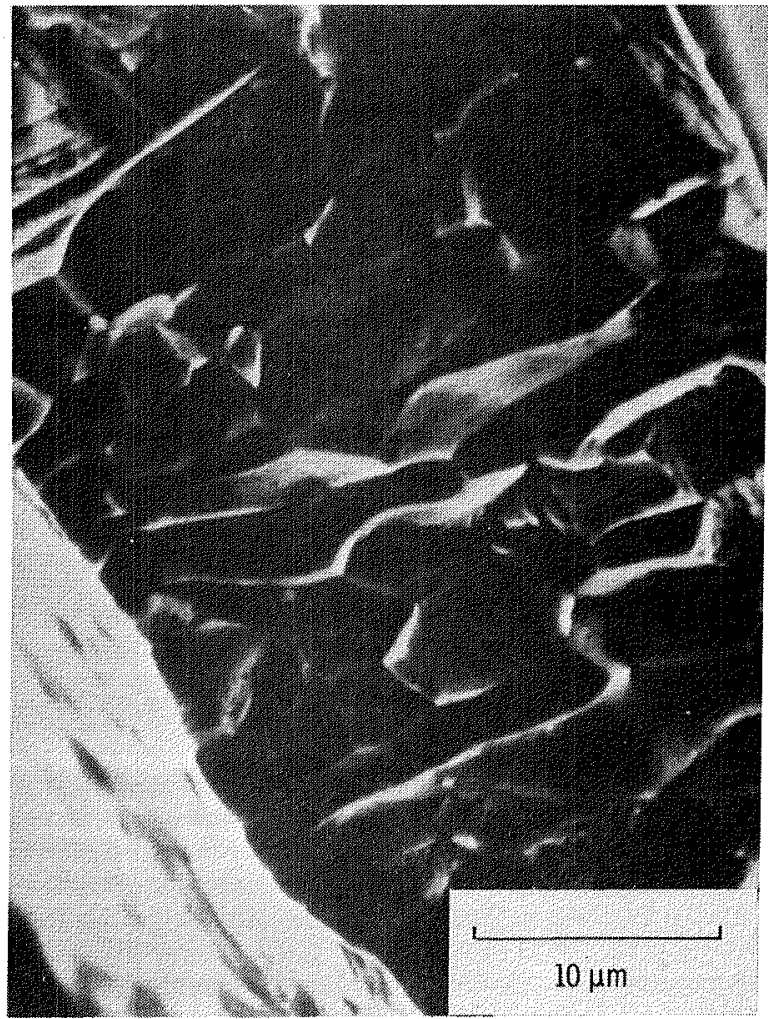

(b) Heat treated $1 \mathrm{~h}$ at $1273 \mathrm{~K}$.

Figure 20. - Comparison of fracture surfaces of NiAl. 


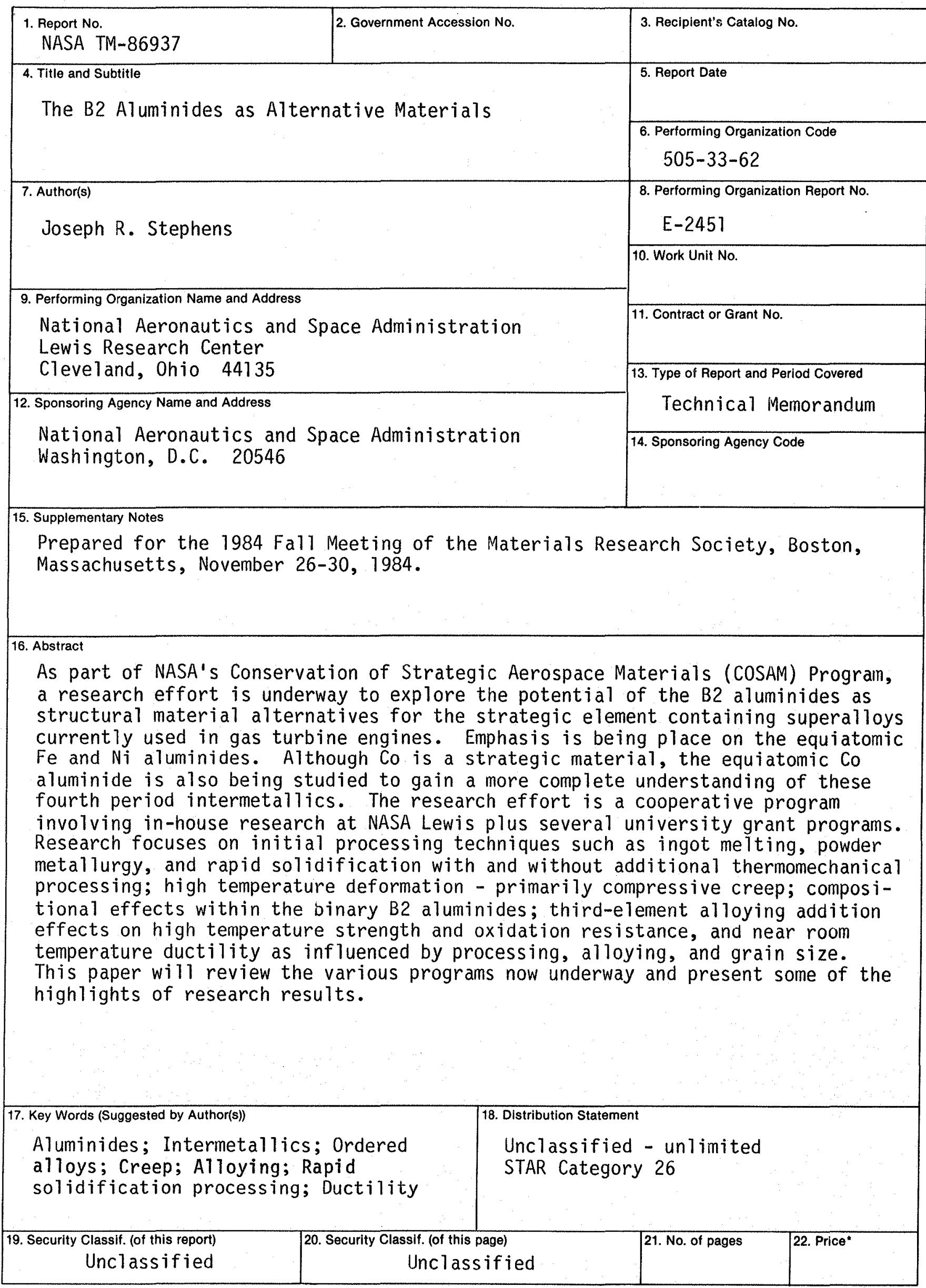

* For sale by the National Technical Information Service, Springfield, Virginia 22161 
End of Document 